\title{
Human Brain Quantum Psychology (HBQP) to use Brain as Virtual Time Machine (VTM)
}

\author{
Sadique Shaikh ${ }^{1 *}$ and Safeena Khan ${ }^{2}$ \\ ${ }^{1}$ Department of Psychology, ISTM Mumbai, MS, India \\ ${ }^{2}$ Department of psychology, Government College of Engineering, MS, India \\ *Corresponding author: Sadique Shaikh, Department of Psychology, ISTM Mumbai, MS, India
}

Received: 泚 October 15, 2019

Published: 㯺 October 22, 2019

\section{Introduction}

Being outstanding scientist and successful researcher after my huge experience I came to write this fact, what you are just because of thoughts process leads to your thinking and in result you are get your view and visuals to see your universe (Androphobic Principle: our universe result of consciousness) which completely different appearance from other one and it's not a science fiction or philosophy it's a "Human Brain Quantum Psychology (HBQP)". Now what HBQP, how its work and how it's correlate with the concept of "Virtual Time Machine (VTM)" discussed in this writeup. In general human psychology practitioners as well as mankind themselves only aware themselves with their entity and existence on planet earth and treating self only a part of earth which is a planet just like particle in universe and exist in universe. Hence unaware with the fact they are not only part of planet earth but more than of entire universe (Figures 1-3). Therefore in every think , act, thoughts, feelings, emotions, perceptions, response, stimuli's and action only relevance to earth not to universe but in fact we know or we don't know our psychology working on the principles of Quantum Mechanics and Space Physics, after all we are active part of this universe and every visuals at every second front of us because of our quantum thoughts which develop our Quantum Psychology which is accepted and executed by universe what we knew as our "Life" as we want or don't want based on your thoughts and feelings and your brain is a machine for the production of the same. Hence as you thoughts according to it universe develop your Quantum Psychology and you will see that pictures in form of desires, needs, wish, work accomplishment and all of these because of "Human Brain Quantum Psychology (HBQP)" where thoughts frequencies are the command to universe for your life whereas Quantum Mechanics channel between human brain and universe to develop what mental model and life every humankind at the time want to live. Now after this I want to demonstrate you the idea how brain can behave like "Virtual Time Machine (VTM)" using Universe, Quantum Mechanics, Law of Attraction, Anthrophobic principles and Human Brain Quantum Psychology (HBQP) depicted in below model.

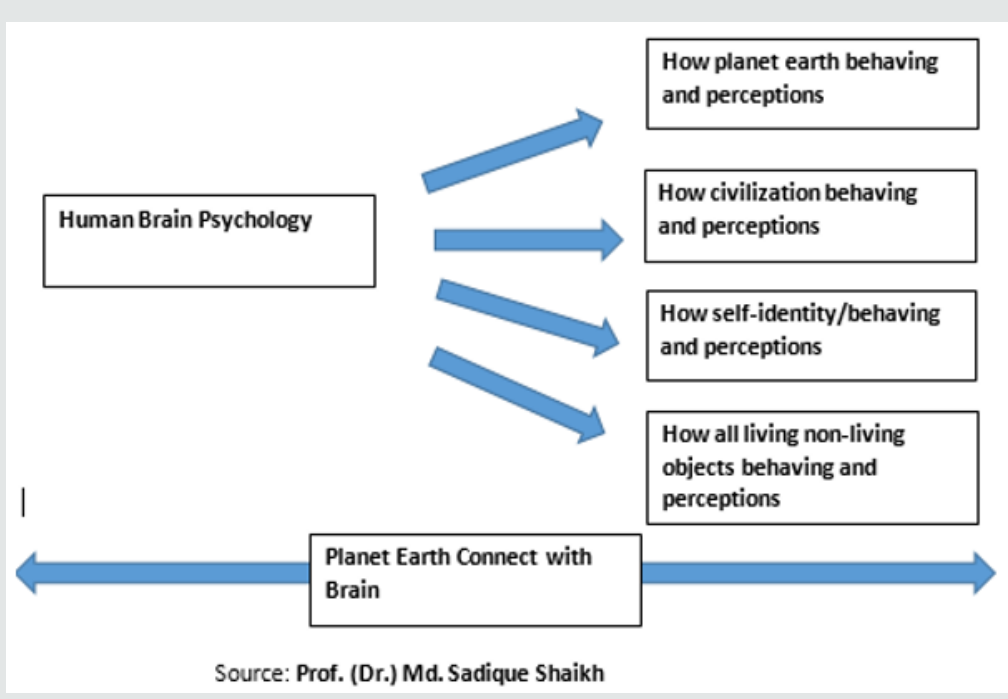

Figure 1: Human Brain psychology Life cycle. 


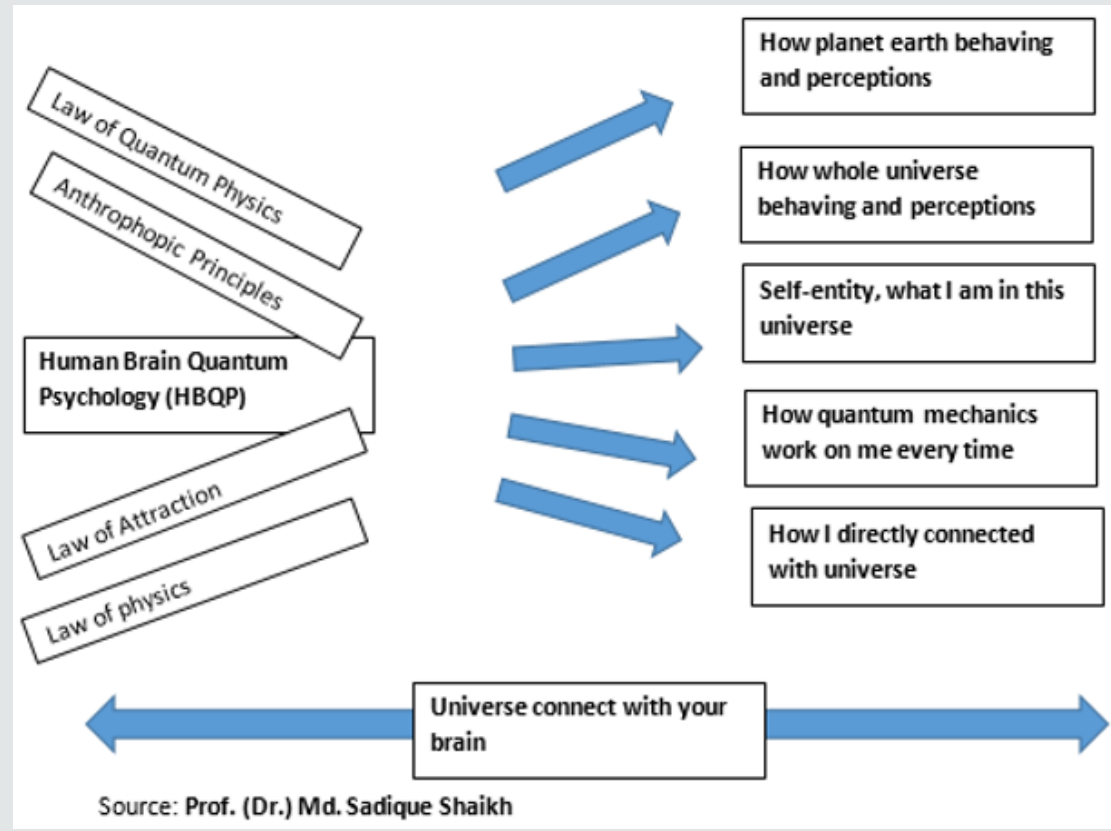

Figure 2: How to plan human brain perceptions.

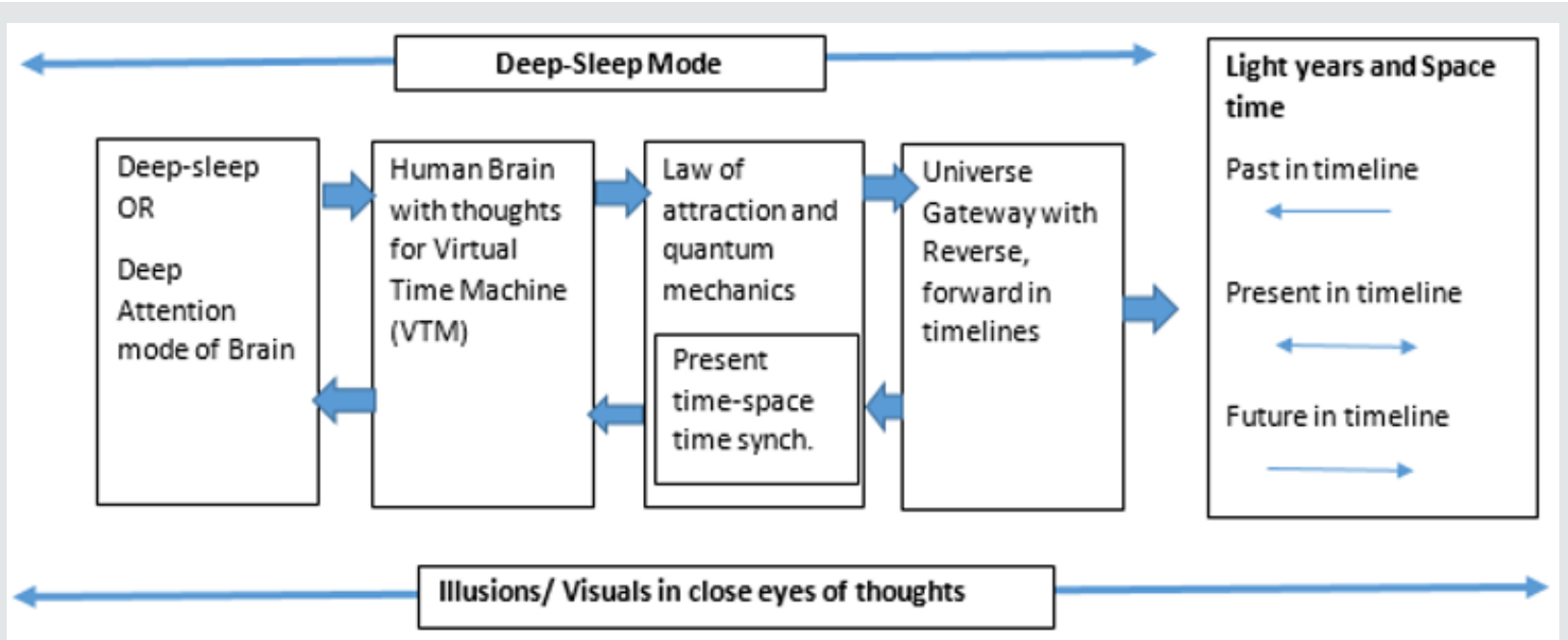

Source: Prof. (Dr.) Md. Sadique Shaikh

Figure 3: Deep-Sleep Mode.

Mankind since longtime trying to research and explore the concept of physical time machine but not focusing attention on their dreams which are the visuals/pictures/science of past, present or future which everybody used to do so. Hence my concept originated from dreams to define "Virtual Time Machine (VTM), of course virtual time machine you can say dream or dream-like but not the dream surely due to the one biggest reason and difference "Dreams occurred in sleep unintentionally and no control it might be good or bad or else, but in Virtual Time Machine (VTM) we can only dream intentionally what we thought and want to dream with entering in that era of time virtually via your dreams". Hence can say dream is the source to enter you in Virtual Time Machine in what time you want to enter with illusions/visuals/moving pictures of it scene like reality. For the concept you need deepsleep, like hypnotism, attention, calmness with thoughts with time in which you want enter and will put you with law of attraction in it with present-time space-time synching via connecting to universe gateway to the universe using law of quantum mechanics to reverse and forward your timeline in space timeline and light years and put you in visuals like virtual reality in past, present and future timeline witching and tuning and Universe back it to you in your brain like Virtual Time Machine (VTM). 


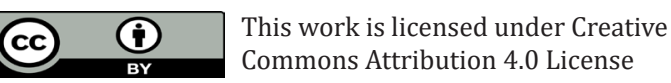

To Submit Your Article Click Here: Submit Article

DOI: $10.32474 /$ SJPBS.2019.03.000153

\begin{tabular}{|l|l|}
\hline SJPBS & $\begin{array}{c}\text { Scholarly Journal of Psychology } \\
\text { and Behavioral Sciences }\end{array}$ \\
Assets of Publishing with us
\end{tabular}

